\title{
The effects of hedonic and utilitarian values on e-loyalty: Understanding the mediating role of e- satisfaction
}

\author{
Mohammed Al Doghan and Abbas N Albarq ${ }^{a}$
}

${ }^{a}$ School of Business, Management Department, King Faisal University, Saudi Arabia

\section{H R O N I C L E}

\section{Article history:}

Received: October 26, 2021

Received in revised format: No-

vember 22, 2021

Accepted: January 12, 2022

Available online: January 142022

Keywords:

Hedonic Shopping Value

Utilitarian Shopping Value

E-retailing

E-satisfaction

E-loyalty

\section{A B S T R A C T}

\begin{abstract}
The purpose of this paper is to examine effects of hedonic and utilitarian aspects of consumer behaviour toward e-loyalty and how e-satisfaction plays a mediating role between them. A survey method was adopted to test the research model. The primary data for the survey was collected during January 2021, using the convenience sampling approach, from business school students. The structural equation modelling method was used to analyse the data with AMOS 22.0 software. The measurement model was estimated through a confirmatory factor analysis before testing the structural model framework and hypotheses (response rate 94.3\%, $n=264$ ). The results showed that hedonic and utilitarian shopping values have great influence in shaping e-satisfaction. The study also highlights the importance of mediating the role of e-satisfaction between shopping values and e-loyalty. This research highlights why and how 'satisfaction with website' matters in the contribution of shopping values to behavioural outcomes by presenting its mediating role. The study offers implications and suggestions to e-retailers by specifying characteristics that should be given more consideration in order to increase online consumer e-satisfaction and e-loyalty. It also contributes to the present body of knowledge on shopping and buying behaviour in the online context, especially for those who have theoretical and managerial interests on the subject in emerging economies like Jordan. The novelty of the paper comes from the fact that it cumulatively captures the factors influencing online consumers' loyalty in the Jordanian context, apart from validating the mediating role of e-satisfaction.
\end{abstract}

\section{Introduction}

The internet has caused a rapid shift in the marketing industry toward adopting multichannel retail strategies. Most consumers have transitioned from offline shopping to online shopping because of the convenience and ease offered by e-commerce websites. Businesses are expeditiously adapting to this change and are using the internet to connect and communicate with their customers, thereby reducing marketing costs and enabling customers to provide feedback regarding their products and services. The industry has seen exponential growth since the spread of the coronavirus, as shoppers are increasingly carrying out online transactions. The internet not only acts as a safe alternative but also offers many other services and benefits that are not available via traditional shopping methods. This has enabled firms to cater to their consumers' needs effectively and to develop a distinguished relationship with them (Brakman et al., 2020). Consumers tend to perceive different levels of hedonic shopping value, utilitarian shopping value, and purchase intention across channels, as channels differ in their constraints and advantages (Nopnukulvised et al., 2019). During recent years, Jordan has witnessed advancements in its information and communication infrastructure. However, Jordanians continue to face barriers regarding online shopping due to

* Corresponding author.

E-mail address: dr.abbasalbarq@yahoo.com (A. N. Albarq)

(C) 2022 by the authors; licensee Growing Science, Canada. doi: $10.5267 /$ j.ijdns.2022.1.005 
harboured concerns that influence their attitude toward the technology (Ahmad, 2016). Alsoud and Ismail (2018) state that "online purchasing in Jordan faces many demanding situations, Jordanian clients are coin orientated, and using online purchasing is lowering 12 months by way of year." There are many factors linked to this problem. Misleading information, unavailability of merchandise, lengthy ordering processes, untrustworthy website content, and the unavailability of alternative delivery strategies, as well as inconsistent font sizing and language, have left Jordanians dissatisfied with online purchasing and e-trade websites (Hassan \& Morris, 2017). Many researchers have tried to study the boundaries of Jordan's e-trade to expand them. Despite this, the literature does not show a complete image of its e-trade adoption. The reason for this may be because there are limited sources of information available regarding e-commerce in Jordan. Despite the provision of e-commerce websites in Jordan, the Ministry of Information and Communications Technology (2016) stated that the purchases among Jordanians and Jordanian organizations online are very low compared to that among Jordan's foreign suppliers. Thus, the question arises, why do Jordanians distance themselves from online purchasing when the spread of the internet in Jordan is extensive, particularly compared to other Middle Eastern nations? This can only be explored by gaining a deeper and strategic understanding of the determinants of online satisfaction and e-loyalty. To this end, online retailers must determine the factors affecting the satisfaction of customers and examine the relationship between satisfaction and e-loyalty. There are few studies available that identify these determinants, although Jordanian e-commerce is witnessing exponential growth. The reason is that most studies have been carried out in the context of developed Western economies (Ha \& Stoel, 2012), and their findings are not applicable to the Jordanian context due to cultural differences (Albarq, 2014). Vijay et al. (2019) claim that the cultures adopted by shoppers in different national markets positively affect the selection and preference of portals; in other words, one's culture can directly affect attitudes, beliefs, and online purchase intentions when selecting an online portal. Hence, this gap calls for a study tailored to the Jordanian context to determine the factors that affect the e-satisfaction and eloyalty of consumers. The first step toward comprehending the dynamics of the market involves in-depth research about consumer behaviour and patterns. The industry has continuously strived to fulfill and exceed all shopper expectations; thus, considering the influence of national culture on consumer behaviour is of paramount importance. The findings of previous studies conducted in this field fail to illustrate the situation in the context of the Jordanian market. This study aims to draw a connection by observing the effects of hedonic and utilitarian values on e-loyalty and the mediating role of e-satisfaction in the Jordanian setting. We believe that our study makes a significant contribution to the literature because despite the fact that many researchers have tried to study the boundaries of Jordan's e-trade to expand them, the literature does not show a complete image of its etrade adoption. This study aims to fill that gap by providing new marketing insights on this emerging market. Therefore, this study aims to draw a connection by observing the effects of hedonic and utilitarian values on e-loyalty and the mediating role of e-satisfaction in the Jordanian setting.

\section{Literature Review}

\subsection{Shopping Values}

Babin et al. (1994) define shopping values as the outcome of a shopping experience. They propose two characteristics of consumer behaviour that constitute shopping values: hedonic and utilitarian benefits. Purchase intention and shopping experiences are modelled by these values depending on the shopper, product, shopping condition, and interaction (Chung, 2015). Babin et al. (1994) also point out that both hedonic and utilitarian values can come into play simultaneously in one purchase experience. Utilitarian values are characterized by practical applications and the needs of consumers whereas hedonic values are characterized by pleasure, fun, and enjoyment. Based on the analyses of researchers who have strived to define shopping values accurately (Choi, 2017; Nopnukulvised et al., 2019; Vijay et al., 2019), the concept has many aspects and varies depending on the state of affairs. An interesting claim is put forward by Fischer and Arnold (1990), who state that consumers shop like they work, and they enjoy the experience of shopping. This highlights the distinctive and assorted aspects of consumer behaviour regarding shopping ventures. However, only considering the apparent benefits obtained upon receiving a product or service is not sufficient (Overby \& Lee, 2006; Vijay et al., 2019). Hence, the instrumental result (utilitarian) should be examined along with the experiential result (hedonic). In their study, Batra and Ahtola (1991) identify utilitarian and hedonic benefits and develop a measurement scale to classify buyer intentions and attitudes. Their work is based on the concept of experiential consumption reported by Hirschman and Holbrook (1982), who suggest that consumer behavior represents personalized states through various symbolic meanings, hedonic responses, and esthetic variables. Hedonic consumption is a novel perspective that challenges the traditional use of logical processing. When making a purchase, consumers tend to assess both types of shopping values. For some consumers, the practical use value outweighs the hedonic aspect, whereas others may be moved by the emotional pleasure that the purchase offers.

\subsection{Hedonic and Utilitarian Values}

Irani and Hanzaee (2011, p. 92) stated that 'utilitarian value is task oriented and cognitive in nature, consumers perceive utilitarian value by acquiring the product that necessitated the shopping trip'. Hamzah (2013) also claimed that utilitarian shoppers are motivated based on cognitive activities and goal-oriented tasks. Thus, utilitarian purchasing behavior is more logical, rational, planned, part of daily routine and always included in purchases. This sentiment has also been expressed by Sangkoy and Tielung (2015) stating that 'a consumer receives utilitarian shopping value when he or she obtains the needed product, and this value increases as the consumer obtains the product more effortlessly'. The hedonic value of a shopping 
experience evokes feelings of cheerfulness and excitement. It triggers the perception that shopping is emotionally useful (Hirschman and Holbrook, 1982), and the purchased product or service not only serves a purpose but also takes care of emotional needs. Thus, this value is more subjective than the utilitarian value. Compared to utilitarian value, hedonic shopping value is more subjective and individualistic. Vijay et al. (2019) assert that the hedonic value may provide consumers the benefit of a product without even having to purchase it. Conversely, the utilitarian value denotes the essential purpose of making a purchase. It highlights the obligatory aspect of the shopping venture. Yuksel (2007) states that the utilitarian value satisfies desire in its actual state. In other words, the desire satisfied through utilitarian utility is generated by the consumption desire that promotes the shopping experience or the product. Its value is perceived through fun and pleasure as opposed to goal achievement (Hirschman \& Holbrook, 1982). Bakirtas and Divanoglu (2013) state that Hedonic consumption signifies the joy and pleasure the consumer expects from shopping. As the expectation from shopping is different for each consumer, so is the feeling experienced during shopping. Some of the consumers are affected by various motivational aspects in order to get joy and pleasure from shopping. In a similar context, Babin et al. (1994) defined hedonic shopping value as perceived entertainment and emotional worth provided through shopping activities. Hedonic shopping value reflects the pleasure, joy and emotional worth of shopping. Hedonic consumption is based on hedonism.

Previous studies have asserted that consumer behaviour is a union of hedonic and utilitarian values (Liu and Forsythe, 2010; Choi, 2017; Vijay et al., 2019). The hedonic value is experimental and involves feelings of excitement, delight, and fun when making a purchase. Choi (2017) discusses the role of the two shopping values in shaping consumer behaviour. Also, many studies have explored the stimulation of shoppers' purchase intention based on these two values (Sorce et al., 2005; Kim and Eastin, 2011). The influence of the hedonic and utilitarian values can vary shoppers' expectations of their online shopping experiences. Consumers that are oriented toward utilitarian values tend to inspect the practical and essential features of products, such as their price, quality, usability, and associated tasks (Sorce et al., 2005). However, consumers that are oriented toward hedonic values tend to explore e-commerce sites and products that make them feel elated. Vijay et al. (2019) and Sirakaya-Turk et al. (2015) state that the purchase of products that fulfil the hedonic expectations of a buyer increases the consumer's motivation and focus during that time. It is also linked to an increase in the frequency of a consumer's online business transactions regarding goods and services (Bui and Kemp, 2013). In addition, it is suggested that an e-commerce website's user interface and clarity play significant roles in regulating the utilitarian aspect of consumer behaviour and impact the satisfaction of the buyers (Hausman and Siekpe, 2009). In consideration of these findings, the following hypotheses are proposed:

\section{$\mathbf{H}_{1}$ : The hedonic shopping value positively influences e-satisfaction. \\ $\mathbf{H}_{2}$ : The utilitarian shopping value positively influences e-satisfaction.}

\subsection{E-Satisfaction and E-Loyalty}

Godefroit-Winkel et al. (2019) define satisfaction as a psychological state of mind that is activated in response to a positive experience. Retailers aim to fulfil the needs and wants of their customers to achieve their satisfaction. Business organizations are advised to have personal interactions with their clients for the same purpose (Cui et al., 2017). "E-satisfaction or electronic satisfaction is a consumer's feeling of contentment regarding a shopping experience with an e-commerce website" (Anderson and Srinivasan, 2003, p. 125). E-satisfaction leads to purchases and repurchases, thus ensuring e-loyalty toward a specific website. Oliver (1999, p. 233) defines customer loyalty as "a deeply held commitment to rebuy or re-patronize a preferred product/service consistently in the future, thereby causing repetitive same-brand or same brand-set purchasing, despite situational influences and marketing efforts having the potential to cause switching behaviour". Against the same backdrop, e-loyalty is defined as "the customer's favourable attitude toward an electronic business resulting in repeat buying behaviour" (Anderson and Srinivasan, 2003). It is also emphasized that satisfaction is a great instigator of loyalty. Many factors determine the e-loyalty of a consumer. For example, the user interface or the data displayed on a website plays a significant role in whether or not a consumer will revisit (Cui et al., 2017). A website's design, reliability, shopping values, and customer service also contribute to consumer e-satisfaction (Godefroit et al., 2019). To investigate the motivation behind e-loyalty, Chiu et al. (2009) utilize the technology acceptance model and find that justice-related elements have a strong impact on the loyalty and satisfaction of consumers. Luo and Ye (2019) establish that satisfaction derived from a firm's online store results in consumers' repeat and regular return purchases. Shankar et al. (2003) illustrate that e-loyalty toward any online retailer is the consequence of an amalgamation of numerous service encounters, website portal experience, and e-satisfaction. Godefroit et al. (2019) confirm the association between e-satisfaction and purchase intentions. Vijay et al. (2019) find this relationship to be positive. Thus, based on this discussion, the following is hypothesized:

\section{$\mathbf{H}_{3}$ : E-satisfaction positively influences consumer e-loyalty.}

Fig. 1 reports the conceptual framework and hypotheses. Accordingly, it has been proposed that the two independent variables - hedonic shopping value (HSV) and utilitarian shopping value (USV) - have a direct significant positive influence on the dependent (mediating) variable e-satisfaction. E-satisfaction further influences the final dependent variable e-loyalty. It is proposed that these two independent variables do not have any direct significant influence on e-loyalty but rather have an indirect influence (through e-satisfaction) on e-loyalty. 


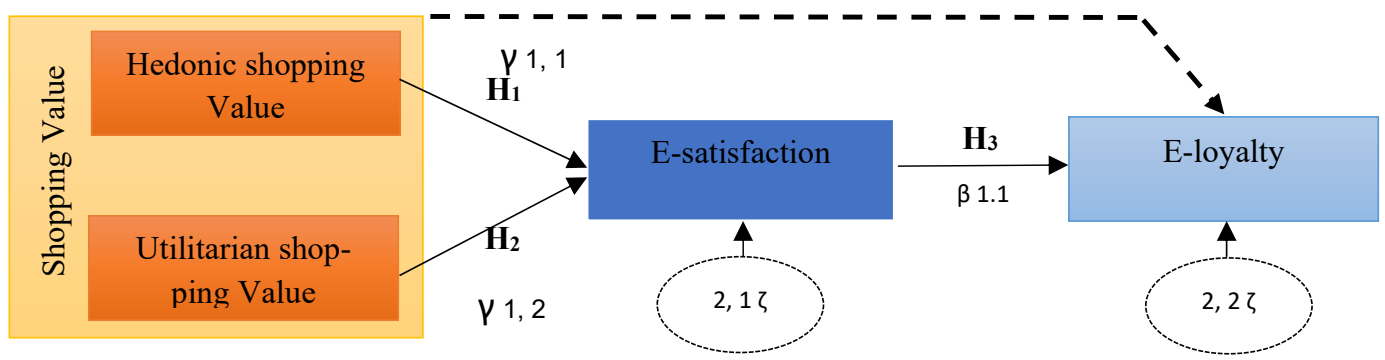

Fig. 1. Conceptual framework and hypotheses

\section{Methodology}

\subsection{Survey Instruments}

The survey instruments were generated using verified items developed by previous studies to measure the identified constructs. A review of the appropriateness of the constructs and respective items was conducted and 18 statements were selected to test all constructs. The hedonic shopping value was assessed using a scale developed by Babin et al. (1994) that consists of four evaluation items: excitement to shop online, pleasure gained from shopping, comparison with other activities, and need verses want. The utilitarian shopping value was measured using a scale developed by Babin et al. (1994) that consists of five evaluation items: optimal price and quality of purchase, success of purchase, specific searching, essential shopping, and sense of accomplishment. To compute e-satisfaction, a modified three-item scale developed by Bhattacherjee (2001) was employed for the following: performance of the website, experience with the website, and overall satisfaction with the purchase experience. Finally, to assess e-loyalty, a six-item scale that evaluated the consumer's first choice, favouritism, best experience, probability of switching, frequency, and service opinion was adapted from Anderson and Srinivasan (2003). A 7-point Likert scale with (1) representing strongly disagree and (7) representing strongly agree was used to measure each of the items. The instrument was tested with the help of 24 consumers who had experience with at least four online shopping stores. The items were checked for propriety and were refined accordingly. The questionnaire was then translated to Arabic and thereby made available in two languages (English and Arabic) for administering in Jordan. The dimensions of each construct were recognized and shared with a two-member panel of control specialists from Jordan universities, as well as marketing consulting companies, to ensure the validity of the questionnaire. Necessary changes were made according to their suggestions.

\subsection{Data Collection/Sample}

Primary data was collected during January 2021 from students of a premier business school of Jordan University, located in central Jordan. The survey instrument (questionnaire) was administered to 280 respondents who were selected using the convenience sampling approach. The respondents were first asked about their shopping experience on popular e-retailers such as Opensooq.com, Amazon, and eBay. The prerequisite condition for participating in the online survey was that the respondents must have shopped through the online medium at least twice in the last three months. Upon confirmation of this, they were asked for their consent to take part in the survey. The respondents were requested to complete the instrument keeping their experience with their specific and preferred online retailer in mind. In all, 264 usable questionnaires were received from the respondents. The demographic profile of the sample is shown in Table 1 . Of the 264 respondents, $55 \%$ were females and nearly $85 \%$ of the respondents were between 21 to 30 years old. Approximately $78 \%$ of the respondents had a monthly family income of more than JOD 600 (USD 850). With respect to shopping frequency, $59 \%$ of the respondents visited an online retailer $1-5$ times on average in a month, and $20 \%$ of the respondents frequented sites $6-10$ times in the same period.

Table 1

Scales used

\begin{tabular}{ll}
\hline Construct & Studies \\
\hline Hedonic Shopping Value & Babin et al. (1994) \\
Utilitarian Shopping Value & Babin et al. (1994) \\
E-Satisfaction & Bhattarcherjee (2001) \\
E-Loyalty & Anderson and Srinivasan (2003) \\
\hline
\end{tabular}

\subsection{Analysis}

The Structural Equation Modeling (SEM) method was used to analyze the data using AMOS 22.0 software. As suggested by Hair et al. (2006), the measurement model was estimated through a confirmatory factor analysis (CFA) before testing the structural model framework and hypotheses. 


\section{Results}

As previously mentioned, the model consisted of two extrinsic variables - the hedonic shopping value (HSV) and the utilitarian shopping value (USV) - and two intrinsic variables - e-satisfaction and e-loyalty. The three hypotheses proposed in the model (as shown in Fig. 1) were tested. The measurement model consisted of four constructs and illustrated the relationship between observed and unobserved variables, and the validity and prominence of the characteristics of the constructs were tested using the CFA (See Fig. 2).

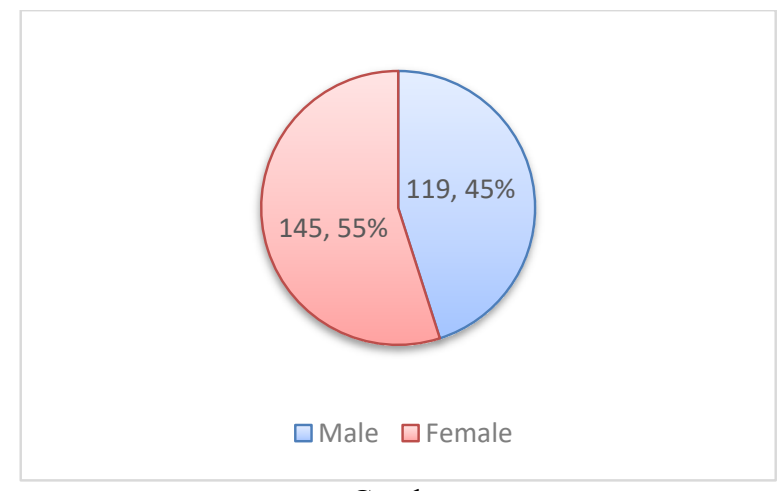

Gender

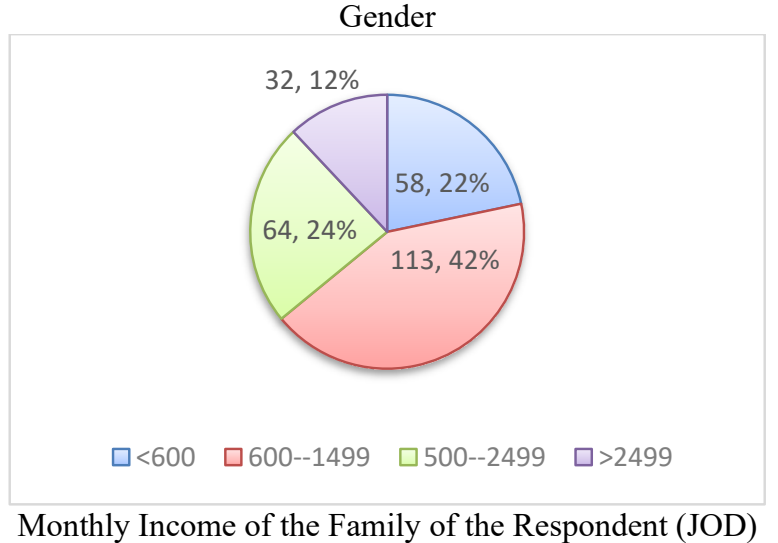

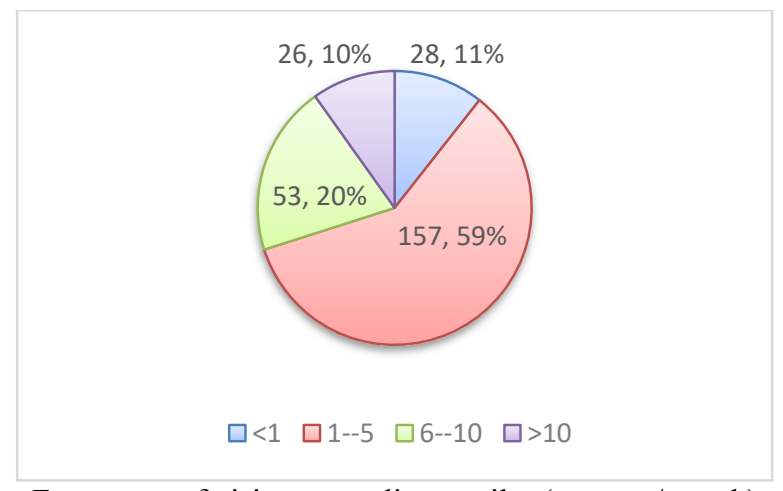

Frequency of visit to an online retailer (average/month)

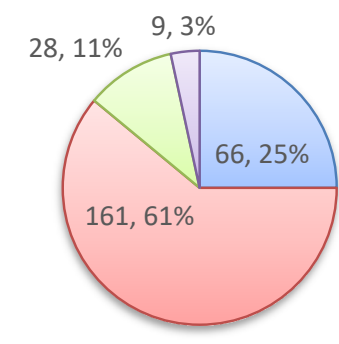

$\square<21 \quad \square 21--30 \quad \square 30--40 \quad \square>40$

Fig. 2. Personal characteristics of the participants

In compliance with the results obtained, the item "I am able to buy what I really need" was removed from the utilitarian shopping value construct (refer to Table 2) because the factor loading for this variable was below 0.50. As shown in Table 3 , other fit indices were also used because the size of the sample was sensitive with regards to chi-square statistics (Hair et al., 2006). A goodness of fit of the model with the data was observed in accordance with various fit indices. The ratio of the chisquare minimum to the degree of freedom (CMIN/df) was below the cut-off criterion of 3.00 (Hair et al., 2006), indicating a good fit between the hypothesized model and the data. Hair et al. (2006) also suggest that the goodness-of-fit index (GFI), adjusted goodness-of-fit index (AGFI), Bentler's comparative fit index (CFI), Bentler-Bonett normed fit index (NFI), and Tucker-Lewis index (TLI) should all be greater than 0.9 . The root mean square error of approximation (RMSEA) value, which should be less than 0.1 , is also utilized.

The t-test or critical ratio was used to determine the statistical significance of the variables. Factor loadings of all items from all four constructs were found to be greater than 0.60 and, hence, notable enough to indicate convergent validity as shown in Table 4. The average variance extracted (AVE) was calculated to further validate the constructs. AVE reflects "the amount of variance that is captured by the construct in relation to the amount of variance due to measurement error" (Hair et al., 2006, p. 45). For the construct to have a reliable structure, its minimum AVE value should be 0.50 . In the case of the present study, the values for all four constructs ranged from 0.55 to 0.75 . From this, it can be concluded that the four variables have good reliability in estimating the latent constructs.

To determine if any two constructs are dissimilar, Hair et al. (2006) suggest testing the discriminant validity. The square root average variance was calculated for every construct and was compared with the factors' correlation coefficients of other factors. Table 3 presents the results of the discriminant validity test. 
Table 2

Measurement model (CFA)

\begin{tabular}{|c|c|c|c|c|c|}
\hline Factor and Items & Factor Loading & $\begin{array}{l}\text { Critical } \\
\text { Ratio (CR) }\end{array}$ & $\alpha$ & AVE & $\begin{array}{l}\text { Construct } \\
\text { Reliability }\end{array}$ \\
\hline Hedonic Value & & & 0.89 & 0.64 & 0.89 \\
\hline Online shopping is always exciting for me & 0.813 & 11.981 & & & \\
\hline $\begin{array}{l}\text { Online shopping gives me more pleasure than what I get } \\
\text { from the products purchased }\end{array}$ & 0.788 & 11.647 & & & \\
\hline $\begin{array}{l}\text { Compared to other things I could do, the time spent } \\
\text { online shopping is/are truly enjoyable }\end{array}$ & 0.843 & 12.359 & & & \\
\hline $\begin{array}{l}\text { I continue to shop not because I have to, but because I } \\
\text { want to }\end{array}$ & 0.753 & Fixed & & & \\
\hline Utilitarian Value & & & 0.86 & 0.57 & 0.85 \\
\hline $\begin{array}{l}\text { The products and services I purchase online are always } \\
\text { right priced and are of good quality }\end{array}$ & 0.638 & Fixed & & & \\
\hline I am successful in my online shopping & 0.669 & 11.501 & & & \\
\hline $\begin{array}{l}\text { While shopping online, I search just the items I am look- } \\
\text { ing for }\end{array}$ & 0.857 & 10.044 & & & \\
\hline I am able to buy what I really need & 0.207 & Deleted & & & \\
\hline $\begin{array}{l}\text { I am able to accomplish just what I want on the online } \\
\text { shopping trip }\end{array}$ & 0.823 & 9.943 & & & \\
\hline E-Satisfaction & & & 0.94 & 0.76 & 0.94 \\
\hline I am satisfied with the performance of the website(s) & 0.817 & 14.688 & & & \\
\hline $\begin{array}{l}\text { I am pleased with the experience of using online shop- } \\
\text { ping website(s) }\end{array}$ & 0.917 & 17.464 & & & \\
\hline $\begin{array}{l}\text { I am satisfied with the purchase experience at this online } \\
\text { retailer }\end{array}$ & 0.906 & Fixed & & & \\
\hline E-Loyalty & & & 0.90 & 0.60 & 0.89 \\
\hline $\begin{array}{l}\text { When I need to make a purchase, this website is my first } \\
\text { choice }\end{array}$ & 0.844 & 12.978 & & & \\
\hline $\begin{array}{l}\text { I believe this is my favourite website to buy the same } \\
\text { kind of product }\end{array}$ & 0.794 & Fixed & & & \\
\hline $\begin{array}{l}\text { To me, this website is the best retail website to do busi- } \\
\text { ness with }\end{array}$ & 0.760 & 11.990 & & & \\
\hline I seldom consider switching to another online retailer & 0.301 & Deleted & & & \\
\hline $\begin{array}{l}\text { I try to purchase at this online retailer whenever I need to } \\
\text { make a purchase }\end{array}$ & 0.730 & 11.669 & & & \\
\hline $\begin{array}{l}\text { As long as the present service continues, I doubt that } \\
\text { would switch to another website }\end{array}$ & 0.845 & 13.922 & & & \\
\hline
\end{tabular}

Table 3

Confirmatory factor analysis of all measurement models

\begin{tabular}{|c|c|c|c|c|c|c|c|}
\hline CFA Model & Items & CMIN/df & TLI & NFI & GFI & AGFI & CFI \\
\hline Hedonic Value & 3 & 1.465 & 0.999 & 0.999 & 0.997 & 0.981 & 0.999 \\
\hline Utilitarian Value & 4 & 1.435 & 0.997 & 0.997 & 0.996 & 0.957 & 0.999 \\
\hline E-Satisfaction & 4 & 1.332 & 0.999 & 0.998 & 0.997 & 0.986 & 0.999 \\
\hline E-Loyalty & 5 & 1.040 & 0.999 & 0.999 & 0.997 & 0.978 & 0.999 \\
\hline
\end{tabular}

The SEM method was then used to analyse the research model in conjunction with the maximum likelihood estimation method. The intrinsic and extrinsic variables were tested to discover the strength of the proposed model and the stated hypotheses. The results shown in Table 4 illustrate a good fit of the hypothesized model. The indices demonstrate the goodness of fit of the model, which makes them an authentic factor for evaluating the hypothesized paths. The values of all the fit indices demonstrate a good fit between the hypothesized model and data.

Table 4

Test of discriminant validity

\begin{tabular}{llll}
\hline Construct & HSV & USV & ES \\
\hline Hedonic Shopping Value (HSV) & $\mathbf{0 . 7 8 1 *}$ & & EL \\
Utilitarian Shopping Value (USV) & 0.362 & $\mathbf{0 . 7 6 8 *}^{*}$ & 0.56 \\
E-Satisfaction (ES) & 0.551 & $0.728^{*}$ \\
E-Loyalty (EL) & 0.667 & 0.347 & 0.585 \\
\hline
\end{tabular}

* Diagonal values represent square root of AVE, all the other values denote the correlation coefficients. 
It is clear from the results shown in Table 5 that the structural model supports the study's hypotheses.

Table 5

Good of Fit of the Hypothesized Model (GOF)

\begin{tabular}{llcc}
\hline Measures & & Fit Indices & Value accepted \\
\hline \multirow{2}{*}{ Absolute Level } & RMSEA & 0.027 & Less than 0.08 \\
& GFI & 0.927 & 0.90 and Above \\
& P- Value & 0.000 & P- Value $\geq 0.05$ \\
\hline \multirow{2}{*}{ Incremental Level } & AGFI & 0.912 & $\leq 0.90$ \\
& CFI & 0.999 & $\leq 0.90$ \\
& TLI & 0.992 & $\leq 0.90$ \\
& NFI & 0.969 & $\leq 0.90$ \\
\hline \multirow{2}{*}{ Parsimonious Level } & CMIN/df & 1.139 & $\geq 2.0$ \\
& $\left(\mathrm{R}^{2}\right)$ & 0.719 & High is better \\
\hline
\end{tabular}

The extrinsic variables, which were hedonic and utilitarian shopping values, demonstrated a strong and favourable influence on e-satisfaction. Furthermore, the total, direct, and indirect effects of the variables on the latent constructs were deconstructed and analysed to explore the effects of hedonic and utilitarian shopping values and e-satisfaction on e-loyalty. In the case of the proposed research model, the extrinsic variables were responsible for $57 \%$ of the total variation in e-satisfaction. The same model allowed $49 \%$ variation in e-loyalty caused by e-satisfaction. Hence, all the determinant variables established a significant direct and/or indirect effect on the latent constructs. Thus, e-satisfaction was found to exhibit a robust direct effect on eloyalty $(\beta=0.37)$. This implies that e-satisfaction plays both direct and indirect roles in building e-loyalty. The effect of the mediating variable, e-satisfaction, on online shopping values and e-loyalty was tested in accordance with the method proposed by Hair et al. (2006). The results are presented in Table 6.

Table 6

Structural model results

\begin{tabular}{lllll}
\hline Hypothesis & Estimate $\boldsymbol{\beta}$ & t-value & $\mathbf{p} \leq$ & Result \\
\hline H1: Hedonic shopping value e-satisfaction & 0.23 & 4.61 & 0.001 & Accepted \\
H2: Utilitarian shopping value e-satisfaction & 0.32 & 5.36 & 0.001 & Accepted \\
H3: e-satisfaction e-loyalty & 0.37 & 5.25 & 0.001 & Accepted \\
\hline
\end{tabular}

Table 7 presents the mediation effect of e-satisfaction in comparing the relationship between known variables and e-loyalty, directly without a mediator, directly with a mediator, and indirectly. The direct effects with and without the mediator are observed to be nearly the same. The indirect column displays a significant effect on e-loyalty. This illustrates that e-satisfaction enhances the significance of all the effects, thereby proving its mediating role. This also confirms that the hedonic and utilitarian shopping values influence an online buyer's e-loyalty via e-satisfaction. The shopper uses those variables to achieve satisfaction with a purchase and, in the process, develops loyalty toward the e-commerce firm. Therefore, the role of the mediator among the online shopping values and e-loyalty is fulfilled by e-satisfaction.

Table 7

Direct, indirect and total effects

\begin{tabular}{lcccccc}
\hline Predictor variables & \multicolumn{3}{c}{ E-satisfaction (Effect) } & \multicolumn{3}{c}{ E-loyalty (Effect) } \\
\hline & Indirect & Direct & Total & Indirect & Direct & Total \\
\hline HV & 0.00 & 0.157 & 0.157 & 0.061 & -0.015 & 0.046 \\
UV & 0.00 & 0.218 & 0.218 & 0.090 & -0.058 & 0.032 \\
E-satisfaction & - & - & - & 0.00 & 0.419 & 0.419 \\
\multicolumn{1}{c}{$\mathbf{R}^{\mathbf{2}}$} & & & & $\mathbf{5 7 \%}$ & & $\mathbf{4 9 \%}$ \\
\hline
\end{tabular}

Table 8 presents the mediating effect of e-satisfaction between the predictor variables and e-loyalty. The significance of direct effect of the variables (both with and without the mediator) are nearly the same. But when we look at the indirect effect all of the variables, they show significant influence on e-loyalty. Directly they are not significant but indirectly (through e-satisfaction all of them are significant). This clearly explains the mediating role of e-satisfaction. The predictor variables do influence online shoppers' e-loyalty through e-satisfaction. It elucidates the fact that an online shopper uses the predictor variables to 
gain satisfaction with the websites and thereby developing loyalty towards the website. Thus, e-satisfaction acts as a mediator among the variables online shopping values and e-loyalty.

Table 8

Mediation effect

\begin{tabular}{llll}
\hline Relationship & Direct without Mediator & Direct with Mediator & Indirect \\
\hline HV ES EL & $0.045(\mathrm{p} \leq .481)$ & $-0.015(\mathrm{p} \leq .761)$ & $0.061(\mathrm{p} \leq .001)$ \\
UV ES EL & $0.011(\mathrm{p} \leq .791)$ & $-0.058(\mathrm{p} \leq .422)$ & $0.90 \leq .001)$ \\
\hline
\end{tabular}

\section{Discussion and Conclusion}

There are only a handful of studies available that examine the effects of various constructs on consumer behaviour and purchase intention in the context of developing world economies like Jordan. To address the existing gaps and shortcomings, this study investigated the factors that impact, directly or indirectly, the satisfaction with and, ultimately, the loyalty to different Jordanian e-commerce firms. The primary goal of the study was to gain insight into the extrinsic and intrinsic factors that influence e-satisfaction and e-loyalty. The findings established a significant relationship between e-satisfaction and e-loyalty. The originality of the study lies in capturing the factors influencing e-loyalty and analysing the strategies that help build this loyalty in an emerging economy like Jordan. The conclusions drawn from the results support the suggested framework and three hypotheses.

The user interface and features offered by a website play a notable role in providing consumers with a hedonic benefit. These factors also facilitate ease of use, as well as contribute to a joyful shopping venture for the consumer. It has been established through this study that hedonic and utilitarian shopping values greatly influence e-satisfaction. Hence, e-retailers are advised to maintain an accurate, up-to-date, complete, and relevant website to ensure consumer loyalty. Today's competition and advancements make it necessary for firms to study the factors that influence the satisfaction and loyalty of their clientele. In agreement with previous studies that examined the same theme (Sirakaya et al., 2015; Cui et al., 2017; Vijay et al., 2019), this study established that hedonic and utilitarian shopping values have a significant positive impact on shoppers' e-satisfaction, which in turn influence e-loyalty.

Furthermore, the present work elucidated the impact of e-satisfaction on e-loyalty, supporting the conclusions drawn by previous studies such as those of Godefroit et al. (2019), Choi (2017), Bakirtas et al. (2015), and Vijay et al. (2019). In contrast to popular belief, it was observed that the utilitarian shopping value was given more importance than the hedonic shopping value in the online context. Hence, retailers must shift their focus to comprehensively providing consumers both benefit types through their website and services. The present study strived to gain loyalty and satisfaction from consumers by studying their behaviour with respect to different facets like online shopping values to provide retailers with implications to enhance their businesses.

Retailers or firms must endeavour to provide both hedonic and utilitarian benefits to consumers, as the study suggests that both constructs have a significant role. Implementing visualization techniques such as 3D models and videos in a website would offer both hedonic and utilitarian values to online shoppers. This can impart a novel and attractive look to the website, providing hedonic value in terms of entertainment, which was found to have the highest influence on shoppers' e-satisfaction. Retailers must also focus on offering goods and services of top-notch quality to offer utilitarian value, which has a great influence on the e-satisfaction and e-loyalty of consumers. By ensuring the information on their websites is truthful, precise, and impartial, e-retailers can significantly increase the length and frequency of their customers' online visits, ultimately increasing their satisfaction and loyalty.

The future scope of this study lies in overcoming its limitations. Because this study was based only in the Jordanian context, it validates the response of only a small fraction of shoppers. Cross-cultural research would be more effective to expand the results of this study. Further limitations can be addressed by incorporating economic environments, markets, or different demographics. Future studies can also explore shopper reactions in the context of different product collections. A two-group analysis can be conducted using SEM to see if the web retailer can act as a moderator of the model. Gender, income, and frequency can also be studied as moderators. To gain a better understanding of online consumer behaviour, the instigation of loyalty with respect to the experience of shopping rather than a specific retailer or firm can be examined in future studies.

\section{Acknowledgements}

The author would like to thank the respondents who participated in this study for taken the time to fill in the questionnaire.

\section{References}

Anderson, R. E. and Srinivasan, S. S. (2003). E-satisfaction and e-loyalty: A contingency framework. Psychology \& marketing, 20(2), 123-138. 
Albarq, A. (2014). An Empirical Investigation to Validate the Technology Acceptance Model TAM in Explaining Intentions to Shop Online in Saudi Arabia Using SEM. Jordan Journal of Business Administration, 10(2), 317-332.

Albarq, A. N. (2006). Intention to shop online among university students in Jordan (Doctoral dissertation, Graduate School, Universiti Utara Malaysia).

Albarq, A. N. (2021). The Effect of Brand Perceptions on Repurchase When Using the E-commerce Website for Shopping. Jindal Journal of Business Research, 10(1), 77-89.

Albarq, A. N. (2021). Effect of Web atmospherics and satisfaction on purchase behavior: stimulus-organism-response model. Future Business Journal, 7(1), 1-8.

Ahmad Nabot, V. G. (2016). Consumer attitudes toward online shopping: An exploratory study from Jordan. Article in international Journal of social ecology and sustainable development, 5(3), 13-24.

Brakman, S., Garretsen, H. and van Witteloostuijn, A. (2020). The turn from just-in-time to just-in-case globalization in and after times of COVID-19 An essay on the risk re-appraisal of borders and buffers. Social Sciences \& Humanities Open, 2(1), 1-6.

Batra, R. and Ahtola, O. T. (1991). Measuring the hedonic and utilitarian sources of consumer attitudes. Marketing letters, 2(2), 159-170.

Bakirtas, H., Bakirtas, I., and Çetin, M. A. (2015). Effects of Utilitarian and Hedonic Shopping Value and Consumer Satisfaction on Consumer Behavioral Intentions. Age Academic Review, 15(1), 91-98.

Bui, M. and Kemp, E. (2013). E-tail emotion regulation: examining online hedonic product purchases. International Journal of Retail \& Distribution Management, 41(2), 136-170.

Babin, B. J., Darden, W. R. and Griffin, M. (1994). Work and/or fun: measuring hedonic and utilitarian shopping value. Journal of consumer research, 20(4), 644-656.

Bhattacherjee, A. (2001). Understanding information systems continuance: an expectation-confirmation model. MIS quarterly, 25(3), 351-370.

Babin, B. J., Darden, W. R. and Griffin, M. (1994). Work and/or fun: measuring hedonic and utilitarian shopping value. Journal of consumer research, 20(4), 644-656.

Chung, Y. S. (2015). Hedonic and utilitarian shopping values in airport shopping behavior. Journal of Air Transport Management, 49, 28-34.

Cui, Y., Niu, J. and Tang, L. (2017). Effect of the online shopping value on e-satisfaction and e-loyalty. Economic Management Journal, 6(1), 9-20.

Chiu, C. M., Lin, H. Y., Sun, S. Y. and Hsu, M. H. (2009). Understanding customers' loyalty intentions towards online shopping: an integration of technology acceptance model and fairness theory. Behaviour \& Information Technology, 28(4), 347-360.

Choi, M. (2017). Shopping tourist satisfaction: an application of hedonic and utilitarian values", Journal of Tourism and Hospitality, 6(5), 1-9.

Fischer, E. and Arnold, S. J. (1990). More than a labor of love: Gender roles and Christmas gift shopping. Journal of consumer research, 17(3), 333-345.

Godefroit-Winkel, D., Diallo, M. F. and Djelassi, S. (2019). Shopping Mall Values, Customer Satisfaction, and Loyalty: The Moderation of Education Level in Morocco. Academy of Marketing Science Annual Conference, Cham. 653-654.

Hair, J. F., Black, W. C., Babin, B. J., Anderson, R. E. and Tatham, R. L. (2006). "Multivariate data analysis 6th Edition", Journal of Abnormal Psychology, 87, 49-74.

Ha, S. and Stoel, L. (2012). Online apparel retailing: roles of e-shopping quality and experiential e-shopping motives. Journal of Service Management, 23(2), 197-215.

Hausman, A. V. and Siekpe, J. S. (2009). The effect of web interface features on consumer online purchase intentions, Journal of business research, 62(1), 5-13.

Hirschman, E. C. and Holbrook, M. B. (1982). Hedonic consumption: emerging concepts, methods and propositions. Journal of marketing, 46(3), 92-101.

Kim, S. and Eastin, M. S. (2011). Hedonic tendencies and the online consumer: An investigation of the online shopping process", Journal of Internet Commerce, 10(1), 68-90.

Liu, C. and Forsythe, S. (2010). Sustaining online shopping: Moderating role of online shopping motives. Journal of Internet Commerce, 9(2), 83-103.

Luo, Y. and Ye, Q. (2019). Understanding consumers' loyalty to an online out shopping platform: The role of social capital and perceived value", Journal of Sustainability, 11(19), 5371.

Nopnukulvised, C., Husamaldin, L. and Bowen, G. (2019). The differences of hedonic shopping value and purchase intention in the multichannel shopping environment for apparel shopping", In Leveraging Computer-Mediated Marketing Environments, IGI Global, 125-142.

Overby, J. W. and Lee, E. J. (2006.) The effects of utilitarian and hedonic online shopping value on consumer preference and intentions, Journal of Business research, 59(11), 1160-1166.

Oliver, R. L. (1999). whence consumer loyalty. Journal of marketing, 63 (11), 33-44.

Sebastianelli, R., Tamimi, N. and Rajan, M. (2008). Perceived quality of online shopping: Does gender make a difference. Journal of Internet Commerce, 7(4), 445-469.

Sorce, P., Perotti, V. and Widrick, S. (2005). Attitude and age differences in online buying. International Journal of Retail \& Distribution Management, 33, 122-132. 
Sirakaya-Turk, E., Ekinci, Y. and Martin, D. (2015). the efficacy of shopping value in predicting destination loyalty. Journal of Business Research, 68(9), 1878-1885.

Shankar, V., Smith, A. K. and Rangaswamy, A. (2003). Customer satisfaction and loyalty in online and offline environments. International journal of research in marketing, 20(2), 153-175.

Nopnukulvised, C., Husamaldin, L. and Bowen, G. (2019). The Differences of Hedonic Shopping Value and Purchase Intention in the Multichannel Shopping Environment for Apparel Shopping. In Bowen, G., \& Ozuem, W. (Ed.), Leveraging Computer-Mediated Marketing Environments, IGI Global, 125-142.

Yaseen, H., K. Dingley, and C. Adams. (2016). Capturing the growth of e-commerce in Jordan using a novel research approach. International Journal of Management and Commerce Innovations, 3(2), 811-827.

Vallejo, S. S. and Marón, N. A. C. (2020). Theoretical and applied study of the psychological and educational effects of lockdown in primary school students in Argentina. Social Sciences \& Humanities Open, 2(1), 1-10.

Vijay, T. S., Prashar, S. and Sahay, V. (2019). The influence of online shopping values and web atmospheric cues on eloyalty: Mediating role of e-satisfaction. Journal of theoretical and applied electronic commerce research, 14(1), 1-15.

Yüksel, A. (2007). Tourist shopping habitat: Effects on emotions, shopping value and behaviours. Tourism management, 28(1), 58-69.

Vijay, T. S., Prashar, S. and Sahay, V. (2019). The influence of online shopping values and web atmospheric cues on e-loyalty: Mediating role of e-satisfaction. Journal of theoretical and applied electronic commerce research, 14(1), 1-15.

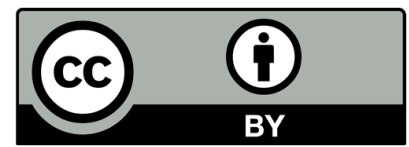

(C) 2022 by the authors; licensee Growing Science, Canada. This is an open access article distributed under the terms and conditions of the Creative Commons Attribution (CC-BY). license (http://creativecommons.org/licenses/by/4.0/). 